\title{
The influence of stimulus phase duration on discomfort and electrically induced torque of quadriceps femoris
}

\author{
Richard E. Liebano ${ }^{1}$, Thaís A. Rodrigues ${ }^{1}$,
} Martha T. Murazawa ${ }^{1}$, Alex R. Ward ${ }^{2}$

\begin{abstract}
Background: Although a number of studies have compared the influence of different electrical pulse parameters on maximum electrically induced torque (MEIT) and discomfort, the role of phase duration has been poorly investigated. Objective: To examine the variation in muscle torque and discomfort produced when electrically stimulating quadriceps femoris using pulsed current with three different phase durations in order to establish whether there are any advantages or disadvantages in varying the phase duration over the range examined. Method: This is a two repeatedmeasures, within-subject study conducted in a research laboratory. The study was divided into 2 parts with 19 healthy young adults in each part.In part 1, MEIT was determined for each phase duration (400, 700, and $1000 \mu$ s), using a biphasic pulsed current at a frequency of $50 \mathrm{~Hz}$. In part 2, stimulus amplitude was increased until the contractions reached $40 \%$ of maximum voluntary isometric contraction (MVIC) and the associated discomfort produced by each phase duration was measured. Results: In part 1 of the study, we found that the average MEITs generated with each phase duration $(400,700$, and $1000 \mu \mathrm{s})$ were 55.0, 56.3, and 58.0\% of MVIC respectively, but the differences were not statistically significant $(p=.45)$. In part 2 , we found a statistically significant increase in discomfort over the same range of phase durations. The results indicate that, for a given level of torque production, discomfort increases with increasing phase duration $(p=.008)$. Conclusions: Greater muscle torque cannot be produced by increasing the stimulus phase duration over the range examined. Greater discomfort is produced by increasing the stimulus phase duration.
\end{abstract}

Keywords: electric stimulation; torque; quadriceps muscle; physical therapy.

Trial Registration: NCT01862393 (ClinicalTrials.org).

\section{HOW TO CITE THIS ARTICLE}

Liebano RE, Rodrigues TA, Murazawa MT, Ward AR. The influence of stimulus phase duration on discomfort and electrically induced torque of quadriceps femoris. Braz J Phys Ther. 2013 Sept-Oct; 17(5):479-486. http://dx.doi.org/10.1590/ S1413-35552012005000112

\section{Introduction}

Neuromuscular Electrical Stimulation (NMES) is a well-substantiated strategy to augment muscle performance in healthy and non-healthy subjects ${ }^{1-9}$. It is also claimed to be useful for delaying or preventing muscle atrophy, increasing muscle thickness, fascicle length, and knee extensor torque in patients with knee osteoarthritis, hastening recovery from knee ligament surgery and from chondromalacia patellae, reducing spasticity and contractures, preventing deep vein thrombosis, and treating a range of clinical conditions ${ }^{10-19}$. The claims are extensive but the published evidence for some of these claims is either lacking or unconvincing ${ }^{20-22}$. Nonetheless, if a condition is known to benefit from induced muscle contraction, it is reasonable to conclude that electrical stimulation intervention, at levels high enough to produce a forceful contraction, is likely to be beneficial ${ }^{23}$.
When attempting to increase muscular strength with electrical stimulation, as with voluntary exercise, there is a strong correlation between the intensity of the muscle contraction and the strength improvement obtained ${ }^{23-25}$. It is also known that the main limiting factor to electrical stimulation for muscle strengthening is the discomfort caused by the stimulating current. Studies have shown successful muscle strengthening after NMES training regimens using 33 to $91 \%$ of maximal voluntary contraction $^{20,25,26}$. To electrically elicit muscular forces within the upper limits of this range requires high current intensities, with accompanying pain that may approach an intolerable level ${ }^{25}$. As a consequence, this modality of muscle training is more efficient when subjects are both highly motivated and have learned by experience to tolerate progressively higher levels of electrical stimulation during training ${ }^{5}$. 
The issue of discomfort is not restricted to strengthening. Patient acceptance and tolerance is an important factor in determining whether electrical stimulation intervention in rehabilitation more generally will be successful. Thus it is important to know whether changing stimulus parameters such as the phase duration will make a difference to either the maximum electrically induced torque (MEIT) or the perceived level of discomfort at lower torque levels. Since achieving high electrically-induced torque is limited by pain, investigators have compared different stimulus waveforms and different types of stimulators in terms of both force production and relative discomfort based on the assumption that a more comfortable stimulus might allow higher stimulation intensities, consequently optimizing the results obtained with NMES ${ }^{24,25,27-30}$.

Two variables that can normally be adjusted by the clinician using a commercially available pulsed current (PC) stimulator are the phase duration of the stimulus and the phase amplitude. At stimulation intensities above the motor threshold, an increase in either the stimulus amplitude or the phase duration will result in an increase in the muscle torque elicited. There will also be an accompanying increase in discomfort. This raises the question of whether it is preferable to increase the phase duration or increase the amplitude in order to increase the torque while minimizing the increase in discomfort. An increase in stimulus phase duration (at fixed amplitude) will certainly produce an increase in the force of muscle contraction. This is because activation of nerve fibers depends on the charge moved across the fiber membrane, and with a longer phase duration, more $\alpha$-motoneurons will experience sufficient charge movement to produce an action potential. But pain will also be increased as greater charge movement means that more $\mathrm{A}-\delta$ and $\mathrm{C}$ fibers will also be activated. An increase in stimulus amplitude (at a fixed phase duration) will also produce an increase in the force of muscle contraction and an associated increase in pain fiber activity due to the greater charge movement. What is not known is whether the effects of increasing the phase charge by increasing the phase duration or phase amplitude are different. The present study was designed to address this issue.

Although a number of studies have compared different kinds of stimulus waveform, there are only a few studies which have directly investigated the effect of phase duration on MEIT ${ }^{31-33}$. Scott et al. ${ }^{31}$ compared monophasic squared-wave pulses with duration of $50 \mu \mathrm{s}$ and $200 \mu \mathrm{s}$, showing that $200 \mu \mathrm{s}$ produces a greater phase charge and a greater MEIT. Similar results were presented by Gorgey and Dudley ${ }^{32}$ when comparing two NMES protocols $(100 \mathrm{~Hz}$ and $450 \mu$ s versus $60 \mathrm{~Hz}$ and $250 \mu \mathrm{s}$ ) on the evoked torque. These authors concluded that the longer pulse duration $(450 \mu \mathrm{s})$ resulted in a greater torque when compared to the shorter pulse duration $(250 \mu \mathrm{s})^{32}$. Gregory et al..$^{33}$ investigated the effects of several combinations of frequencies $(10,20,30,40$, $50,60,70$, and $100 \mathrm{~Hz})$ and pulse durations (100, 200, 300, 400, 500, 600, and $700 \mu \mathrm{s}$ ) on muscle torque production and fatigue. At constant current amplitude, torque increased as pulse duration was increased, and total charge was a predictor of torque production. Higher frequency trains caused greater fatigue. Nevertheless, none of these studies assessed the discomfort produced by different pulse durations, and no studies comparing longer pulse durations were found in the literature. Accordingly, we chose to compare both the MEIT of quadriceps femoris and the discomfort associated with PC of different phase durations using a commercially available stimulator. The purpose of this study was to establish whether, over the range of phase durations investigated, there are any advantages or disadvantages in varying the phase duration in terms of (i) muscle torque production and (ii) associated discomfort.

\section{Method}

\section{Subjects}

Ethics approval for the study was given by the Institutional Review Board (IRB) of Universidade Cidade de São Paulo (UNICID), São Paulo, SP, Brazil (PP 13323922). A convenience sample of undergraduate physical therapy students was recruited from UNICID. All participants were aware of the experimental procedures and gave informed consent. For each of the two parts of the study, separate groups of twenty sedentary healthy university students were recruited as participants (19.5 \pm 3.2 years). The participants were all female, reflecting the gender imbalance in the undergraduate physical therapy student population. Each participant was informed about the aim of the study and given details, including what would be required of them and each gave written informed consent before the experimental measures were made. All participants had previously used and experienced neuromuscular electrical stimulation during electrotherapy classes and were therefore familiar with electrical stimulation.

None of the participants in this study had a history of knee surgery or injury, musculoskeletal, cardiovascular or neurological disease including 
impaired sensation. An exclusion criterion for part 1 of the study was if the participant did not reach MEIT with the stimulator used. Two participants were excluded from the analysis. One participant tolerated the maximum output of the stimulator and was therefore excluded. Another could not tolerate the discomfort of stimulation to $40 \%$ of MVIC and was therefore excluded. Thus, parts 1 and 2 each had 19 participants.

\section{Apparatus}

The stimulator used for the study was a mainspowered, commercially available, constant current unit called Dualpex 961 (Quark Produtos Médicos, Piracicaba, São Paulo, Brazil). The Dualpex was set to symmetric biphasic square pulsed current at a frequency of $50 \mathrm{~Hz}$ ramped up in amplitude for 2 seconds then constant for 4 seconds of 'on' time (part 1) or 6 seconds of 'on' time (part 2). The shorter 'on' time in part 1 of the study was because MEIT was measured, so it was important to minimize the duration of the discomfort, which was maximum tolerable. A longer 'on' time was used in part 2 to allow the subject to better assess the discomfort associated with stimulation at $40 \%$ of MVIC. Stimulus phase durations were set to 400 , 700 , and $1000 \mu \mathrm{s}$. At the frequency used $(50 \mathrm{~Hz})$, these phase durations are not likely to pose a risk of skin irritation or damage ${ }^{22}$. The current was applied to the right quadriceps femoris muscle ${ }^{29,34}$ using two conductive (carbon-impregnated) rubber electrodes (size $10 \times 4.5 \mathrm{~cm}$ ) and electrode gel (Sonic-Plus Gel, Hal Indústria e Comércio Ltda, São Paulo, Brazil). The proximal electrode was placed over the femoral triangle of the quadriceps and the distal electrode was over the motor point of the vastus medialis ${ }^{28}$. Electrodes were secured in place with adhesive tape. A 3-minute interval between each repetition was standardized among the MEITs performed to minimize the effects of muscle fatigue ${ }^{8,35}$.

An isokinetic dynamometer (Cybex Norm 6000, Cybex Division of Lumex, Inc., Ronkonkoma, NY, USA) was used for torque measurement. It was set to isometric mode at an angle of $60^{\circ}$ degrees of knee flexion $^{18,29,36,37}$.

\section{Procedure}

Each participant undertook a 5-minute warm-up on an exercise bicycle before testing ${ }^{36}$, cycling at approximately 75 revolutions per minute with no extra resistance. All participants then performed three maximum voluntary isometric contractions (MVIC) of the right quadriceps femoris muscle ${ }^{29,34,38}$.
Each contraction was sustained for 4 seconds (part 1) and 6 seconds (part 2) and there was a 3 minute rest period between each contraction. The highest of the three torque measurements recorded by the Cybex dynamometer was considered to be MVIC. Subsequently this value was used to calculate maximum electrically induced torque (MEIT) as a percentage of MVIC.

In part 1 of the study, three minutes after the determination of MVIC, maximum electrically induced torque was determined for each phase duration (400, 700, and $1000 \mu$ s). Participants were instructed to relax and neither oppose or assist the contraction. First the amplitude was increased gradually (using continuous output) until the participant indicated that the stimulus intensity was the maximum they were willing or able to tolerate. After a three-minute rest period, the same stimulus amplitude was applied using a two-second ramp-up and four seconds of 'on' time. During the 'on' time, electrically induced torque was recorded. If the participant indicated that they could tolerate a higher stimulus intensity, the amplitude was increased. Once the maximum amplitude was established, three measures were made for each phase duration and the highest value was taken as the MEIT. The order of presentation of the phase durations was randomized so as to avoid order-induced bias. Each electrically elicited contraction was sustained for four seconds, after which there was a rest period of three minutes.

In part 2 of the study, electrical stimulation using phase durations of 400, 700 or $1000 \mu$ s was used. The order of presentation of the three phase durations was randomized to avoid order-induced bias. To avoid muscle fatigue, stimulations were again spaced three minutes apart. First, MEIT was measured (as in part 1). Next the stimulus amplitude was increased until the contractions produced were $40 \%$ of MVIC. The peak amplitude (in $\mathrm{mA}$ ) was recorded and each volunteer rated the associated discomfort using a $10 \mathrm{~cm}$ visual analogue scale (VAS) ranging from zero (no discomfort) to 10 (worst discomfort imaginable).

\section{Data analysis}

Data were analyzed using the SPSS version 14 software package (SPSS Inc., Chicago, IL, USA) and retrospective power analysis as described by Portney and Watkins ${ }^{39}$ using Cohen's ${ }^{40}$ sample size tables. Preliminary analysis found no extreme outliers and Q-Q plots identified that the data were normally distributed. Accordingly, parametric tests were conducted. In part 1 , to better isolate and identify any variation in MEIT with phase duration, 
a one-way, repeated-measures analysis of variance (ANOVA) was conducted. In order to separately examine the effect of MVIC on MEIT, data were further analyzed by regression analysis using raw MEIT values (uncorrected for MVIC) with stimulus phase duration and MVIC as the covariates.

In part 2, linear regression analysis was performed as the three conditions compared (three phase durations) are values chosen from a continuum. Stimulus phase charge was calculated by multiplying the stimulus amplitude (in $\mathrm{mA}$ ) by the phase duration (in $\mu$ s) to give the phase charge in microcoulombs $(\mu \mathrm{C})$. A linear regression analysis of discomfort on phase charge was then performed. To establish whether phase charge or phase duration was the important factor or whether both made some independent contribution, the relationship between phase charge and phase duration was examined, using separate linear regression analyses. Separate analyses were needed as multiple regression cannot be performed unless the factors are independent, and in this case, phase duration and phase charge are not independent.

\section{Results}

\section{Part 1}

Figure 1 shows the variation in MEIT, expressed as a percentage of MVIC, over the three phase durations examined. Again the smallness of the variation is evident. An interesting feature is that although an increase in mean MEIT with increasing phase duration is evident, the variation is small (53 to $58 \%$ of MVIC).

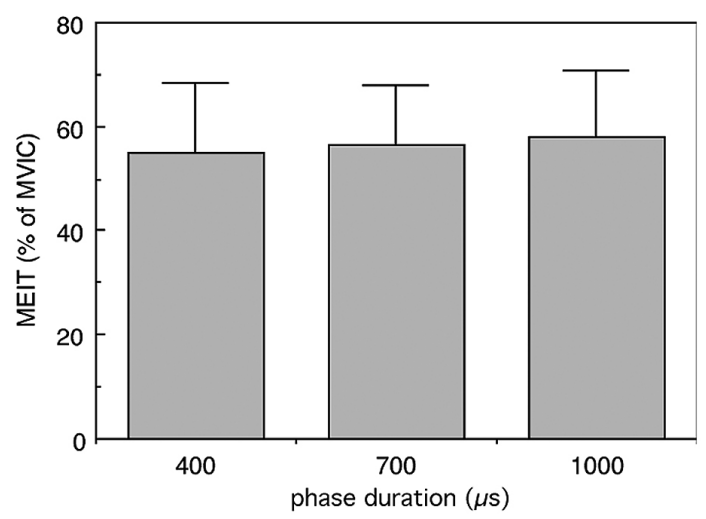

Figure 1. Average MEIT of quadriceps femoris muscle with stimulus phase durations of 400,700 , and $1000 \mu \mathrm{s}$. Torque is expressed as a percentage of maximum voluntary isometric contraction (MVIC). Values shown are means. Error bars are standard deviations.
A repeated-measures ANOVA showed that the between subject variance in MEIT was, as might be expected, significant $(\mathrm{F}(18,2)=7.07, \mathrm{Fc}=1.90$, $p<.001)$, but the variation with phase duration was not statistically significant $(\mathrm{F}(2,18)=0.82, \mathrm{Fc}=3.26$, $p=.45)$. As a consequence, no post-hoc comparisons of phase duration effects were justified.

Compared to the $400 \mu$ s pulse duration, the MEIT was $2.4 \%$ higher at $700 \mu$ s and $5.5 \%$ higher at $1000 \mu$ s. While this suggests an increasing trend, the variation is too small to demonstrate statistical significance with the subject number used. A power analysis was used to estimate the number of subjects that would be needed to demonstrate statistical significance with the effect size found $(d=0.06)^{39,40}$. Cohen' $s^{40}$ tables indicate that to achieve a $p$ value of .05 or less, over 600 participants would have been needed. This indicates that, over the range examined, the variation in MEIT with phase duration is not only statistically insignificant but also clinically insignificant.

\section{Part 2}

Figure 2 shows the variation in discomfort (mean VAS and standard deviation), over the three phase durations examined. Linear regression analysis showed that there is a clear and statistically significant increase in group-averaged discomfort rating (VAS) with phase duration (Pearson's $r=0.34, p=.008$ ). The relatively low value of $r$ indicates that phase duration can account for only a fraction of the variation actually observed. The large error bars reflect a large between-subject variation whilst the very low value of $p$ indicates that, despite this, the increase in discomfort with phase duration is significant.

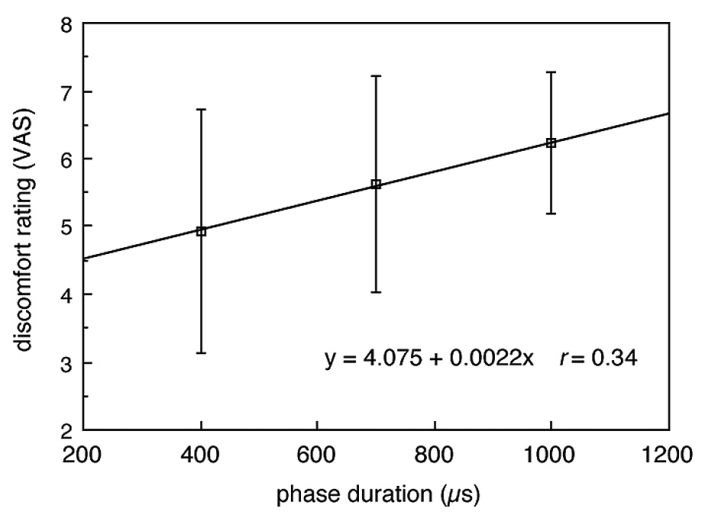

Figure 2. The variation in discomfort (VAS) with phase duration at stimulation intensities sufficient to produce a torque equal to $40 \%$ of MVIC. Values shown are means $(n=19)$. Error bars are standard deviations. 
Figure 3 shows the variation in discomfort (mean VAS and standard deviation), over the three phase durations examined, this time expressed as groupaverage phase charge. Regression analysis again demonstrates significance i.e. that there is a clear and statistically significant increase in discomfort rating (VAS) with phase charge (Pearson's $r=0.28, p=.032$ ) but the correlation is not as high as discomfort rating with phase duration (Pearson's $r=0.34, p=.008$ ).

The significant increase in group-averaged discomfort rating (VAS) with both phase duration (Figure 2) and phase charge (Figure 3) raises the question whether phase duration is the important factor, or phase charge, or whether both contribute independently in determining the discomfort of stimulation. This question could only be answered by conventional statistical analysis (either a 2-way ANOVA or regression analysis) if phase charge and phase duration were independent parameters, which they are not. Phase charge is equal to phase duration $\times$ amplitude $(\mathrm{mA})$. The high correlation between phase charge and phase duration was confirmed by the positive results of a regression analysis (Pearson's $r=0.72, p=.000$ ), meaning that conventional factor analysis would be unable to separate their contributions to the VAS measures.

Data for each phase duration $(400,700$, and $1000 \mu$ s) were therefore examined separately. Scatter graphs of discomfort (VAS) versus phase charge were plotted for each phase duration. These graphs showed no correlation between discomfort and phase charge. By way of illustration, Figure 4 shows a plot of discomfort (VAS) versus phase charge for the $700 \mu$ s phase duration stimulus. The apparent lack of correlation is evidenced by the calculated correlation coefficient (Pearson's $r=0.032, p=.895$ ).

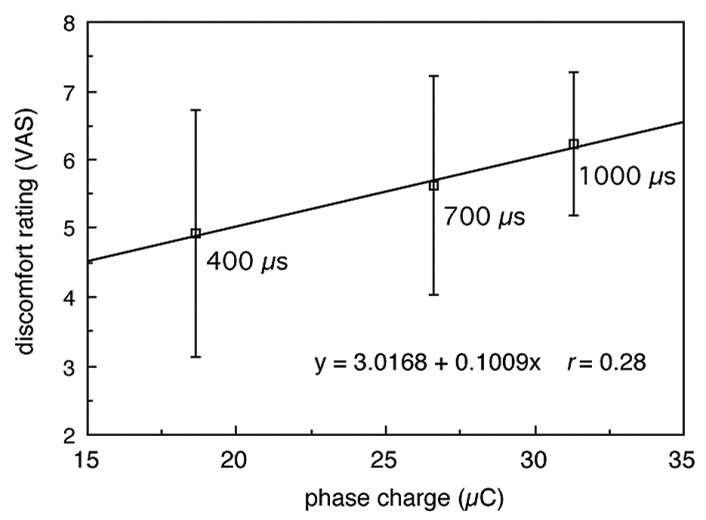

Figure 3. The group averaged variation in discomfort (VAS) with phase charge at stimulation intensities sufficient to produce a torque equal to $40 \%$ of MVIC. Values shown are means $(n=19)$. Error bars are standard deviations.
Similar results were obtained at phase durations of $400 \mu \mathrm{s}(r=0.264, p=.260)$ and $1000 \mu \mathrm{s}(r=-0.110$, $p=.644$ ). The $r$ values seem haphazard, with an average of 0.061 and associated $p$ values which do not even approach significance. It thus seems that there is no significant correlation between phase charge and discomfort if the phase duration is constant. If the phase duration varies, there is a significant variation in discomfort (Figure 2). Hence it is reasonable to conclude that phase duration is the decisive factor and that the variation in discomfort with phase charge (Figure 3 ) is only a secondary consequence.

\section{Discussion}

\section{MEIT and stimulus phase duration}

In part 1 of the study, data analysis showed no significant variation with stimulus phase duration. This contradicts the idea that greater MEIT can be achieved by increasing the phase duration of the stimulus when using longer pulse durations. It appears that increasing pulse duration will only increase the MEIT in a shorter ( $50 \mu \mathrm{s})$ to medium $(450 \mu \mathrm{s})$ pulse duration range $\mathrm{e}^{31,32}$, or when the current amplitude is kept constant during the increase inpulse duration ${ }^{33}$. Over the range of phase durations examined in the present study, the increase in MEIT was both statistically and (based upon the small effect size) clinically insignificant.

\section{Discomfort and stimulus phase duration}

The relative discomfort of different forms of electrical stimulation is clearly a clinically relevant issue. In part 2 of this study, discomfort was

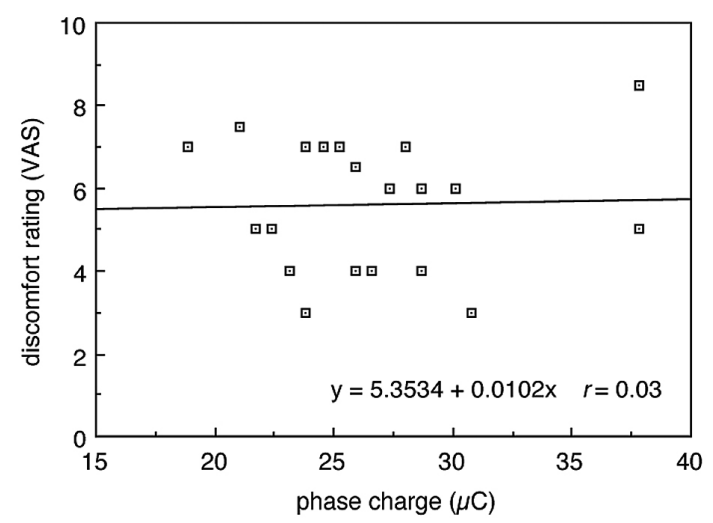

Figure 4. The variation in discomfort (VAS) with phase charge at stimulation intensities sufficient to produce a torque equal to $40 \%$ of MVIC. Values shown were obtained using a stimulus phase duration of $700 \mu$ s. 
measured at a fixed level of electrically induced torque (40\% of MVIC). We found that discomfort, subjectively assessed and reported using a VAS, increases significantly with phase duration over the range examined $(p=.008)$. Strength-duration curves for sensory, motor, and pain tolerance thresholds converge at longer phase durations, i.e. there is less separation between pain and motor thresholds, so the increase in discomfort with phase duration is perhaps not unexpected ${ }^{41-43}$.

\section{MEIT values in the present study}

A number of studies have shown that electrical stimulation is useful for improving muscle performance but the findings indicate that electrical stimulation will only be effective if sufficient torque (expressed as \% of MVIC) is induced by the electrical stimulation $^{22}$. Several authors reported positive results for strengthening with electrically induced torques ranging from $33 \%$ to $91 \%$ of MVIC $^{5,10,24,26,30,44,45}$. The values obtained in part 1 of this study (mean $56 \%$ of MVIC, range 30-86\%) are well within the range of these positive findings. The discomfort measurements (VAS) in part 2 of the present study were taken at electrically induced torques equal to $40 \%$ of MVIC: again within the effective range.

A perhaps surprising finding of the present study is that little increase in MEIT can be achieved by increasing the phase duration of the stimulus. Certainly if the stimulus amplitude (current or voltage) is kept constant, an increase in phase duration will result in a proportional increase in the charge per pulse and hence greater recruitment of motor nerve fibers and a more forceful contraction ${ }^{21,22,33,43}$. However, there will also be greater recruitment of pain fibers,so in practice, because MEIT is dictated by discomfort associated with the stimulation, the maximum tolerable stimulation amplitude may decrease significantly with increasing phase duration. It appears that, over the range of phase durations examined in the present study, the increase in discomfort with phase duration almost completely negates the potential increase in MEIT.

\section{Implications}

Our finding that discomfort increases significantly with phase duration but that the corresponding increase in MEIT is not significant raises the question whether there is any advantage in having a choice of phase durations on clinical stimulators to be used for NMES. On the basis of our findings, the answer to this question would be 'no'. There is, however, an important practical issue with commercially available stimulators and that is the maximum output available.
Stimulators have an upper limit to the current they can deliver. At shorter phase durations, a greater stimulus amplitude (current) is needed in order to provide the necessary phase charge (which is the amplitude multiplied by the duration). So if the phase duration is too short, the maximum output of the machine (in $\mathrm{mA}$ ) may not be sufficient to produce a maximal contraction. As noted above, one participant had to be excluded from part 1 of the present study as they had not reached MEIT when maximum output of the stimulator was reached using the shortest $(400 \mu \mathrm{s})$ phase duration. Having the option of increasing the phase duration means that the clinician can always elicit a maximal contraction though the trade-off is increased discomfort with a longer phase duration.

\section{Conclusions}

The results suggest a trend of increasing MEIT with stimulus phase duration but the measured variation was not statistically significant over the range of phase durations examined. Power analysis demonstrated that any variation which might exist is clinically insignificant.

For a fixed level of muscle torque, discomfort increases with increasing phase duration over the range examined. For this reason we advocate use of the shortest phase duration $(400 \mu \mathrm{s})$ to minimize discomfort without compromising torque production.

\section{Acknowledgements}

Special thanks to the subjects who volunteered and participated in this research project.

\section{References}

1. Kramer JF, Mendryk SW. Electrical stimulation as a strength improvement technique: a review. J Orthop Sports Phys Ther. 1982;4(2):91-8. PMid:18810104.

2. Currier DP, Mann R. Muscular strength development by electrical stimulation in healthy individuals. Phys Ther. 1983;63(6):915-21. PMid:6856678.

3. Delitto A, Rose SJ. Comparative comfort of three waveforms used in electrically eliciting quadriceps femoris muscle contractions. Phys Ther. 1986;66(11):1704-7. PMid:3490675.

4. Delitto A, Brown M, Strube MJ, Rose SJ, Lehman RC. Electrical stimulation of quadriceps femoris in an elite weight lifter: a single subject experiment. Int J Sports Med. 1989;10(3):187-91. PMid:2674035. http://dx.doi. org/10.1055/s-2007-1024898

5. Delitto A, Snyder-Mackler L. Two theories of muscle strength augmentation using percutaneous electrical stimulation. Phys Ther. 1990;70(3):158-64. PMid:2406766. 
6. Bircan C, Senocak O, Peker O, Kaya A, Tamci SA, Gulbahar $\mathrm{S}$, et al. Efficacy of two forms of electrical stimulation in increasing quadriceps strength: a randomized controlled trial. Clin Rehabil. 2002;16(2):194-9. PMid:11911517. http://dx.doi.org/10.1191/0269215502cr467oa

7. Petterson S, Snyder-Mackler L. The use of neuromuscular electrical stimulation to improve activation deficits in a patient with chronic quadriceps strength impairments following total knee arthroplasty. J Orthop Sports Phys Ther. 2006;36(9):678-85. PMid:17017273.

8. Stevens JE, Mizner RL, Snyder-Mackler L. Neuromuscular electrical stimulation for quadriceps muscle strengthening after bilateral total knee arthroplasty: a case series. J Orthop Sports Phys Ther. 2004;34(1):21-9. PMid:14964588.

9. Snyder-Mackler L, Delitto A, Bailey SL, Stralka SW. Strength of the quadriceps femoris muscle and functional recovery after reconstruction of the anterior cruciate ligament. A prospective, randomized clinical trial of electrical stimulation. J Bone Joint Surg Am. 1995;77(8):1166-73. PMid:7642660.

10. Hortobagyi T, Lambert NJ, Tracy C, Shinebarger M. Voluntary and electromyostimulation forces in trained and untrained men. Med Sci Sports Exerc. 1992;24(6):702-7. PMid:1602943.

11. Broderick BJ, O'Briain DE, Breen PP, Kearns SR, Olaighin G. A pilot evaluation of a neuromuscular electrical stimulation (NMES) based methodology for the prevention of venous stasis during bed rest. Med Eng Phys. 2010;32(4):349-55. PMid:20171135. http://dx.doi. org/10.1016/j.medengphy.2010.01.006

12. Griffin M, Nicolaides AN, Bond D, Geroulakos G, Kalodiki E. The efficacy of a new stimulation technology to increase venous flow and prevent venous stasis. Eur J Vasc Endovasc Surg. 2010;40(6):766-71. PMid:20650668. http://dx.doi.org/10.1016/j.ejvs.2010.06.019

13. Sahin N, Ugurlu H, Albayrak I. The efficacy of electrical stimulation in reducing the post-stroke spasticity: a randomized controlled study. Disabil Rehabil. 2012;34(2):151-6. http://dx.doi.org/10.3109/09 638288.2011 .593679

14. Lewek M, Stevens J, Snyder-Mackler L. The use of electrical stimulation to increase quadriceps femoris muscle force in an elderly patient following a total knee arthroplasty. Phys Ther. 2001;81(9):1565-71. PMid:11688592.

15. Kim KM, Croy T, Hertel J, Saliba S. Effects of neuromuscular electrical stimulation after anterior cruciate ligament reconstruction on quadriceps strength, function, and patient-oriented outcomes: a systematic review. J Orthop Sports Phys Ther. 2010;40(7):383-91. PMid:20592480.

16. Chen SC, Chen YL, Chen CJ, Lai CH, Chiang WH, Chen WL. Effects of surface electrical stimulation on the muscletendon junction of spastic gastrocnemius in stroke patients. Disabil Rehabil. 2005;27(3):105-10. PMid:15823991. http://dx.doi.org/10.1080/09638280400009022

17. Robertson VJ, Ward AR. Vastus medialis electrical stimulation to improve lower extremity function following a lateral patellar retinacular release. J Orthop
Sports Phys Ther. 2002;32(9):437-43; discussion 43-6. PMid:12322810.

18. Vaz MA, Baroni BM, Geremia JM, Lanferdini FJ, Mayer A, Arampatzis A, et al. Neuromuscular electrical stimulation (NMES) reduces structural and functional losses of quadriceps muscle and improves health status in patients with knee osteoarthritis. J Orthop Res. 2013;31(4):511-6. PMid:23138532. http://dx.doi. org/10.1002/jor.22264

19. Nunes LCBG, Quevedo AAF, Magdalon EC. Effects of neuromuscular electrical stimulation on tibialis anterior muscle of spastic hemiparetic children. Rev Bras Fisioter. 2008;12(4):317-23. http://dx.doi.org/10.1590/ S1413-35552008000400011

20. Delitto A, Snyder-Mackler L, Robinson AJ. Electrical stimulation of muscle: techniques and applications. In: Robinson AJ, Snyder-Mackler L, editors. Clinical Electrophysiology: Electrotherapy and Electrophysiologic Testing. 2nd ed. Philadelphia: Lippincott, Williams \& Wilkins; 1995. p. 121-54.

21. Nelson RM, Hayes KW, Currier DP. Clinical Electrotherapy. 3rd ed. Stamford: Appleton \& Lange; 2003.

22. Robertson VJ, Ward AR, Low J, Reed A. Electrotherapy explained: principles and practice. 4th ed. Oxford: Butterworth-Heinemann; 2006.

23. Stevens-Lapsley JE, Balter JE, Wolfe P, Eckhoff DG, Schwartz RS, Schenkman M, et al. Relationship between intensity of quadriceps muscle neuromuscular electrical stimulation and strength recovery after total knee arthroplasty. Phys Ther. 2012;92(9):1187-96. PMid:22652985 PMCid:PMC3432951. http://dx.doi. org/10.2522/ptj.20110479

24. McMiken DF, Todd-Smith M, Thompson C. Strengthening of human quadriceps muscles by cutaneous electrical stimulation. Scand J Rehabil Med. 1983;15(1):25-8. PMid:6828830.

25. Delitto A, Strube MJ, Shulman AD, Minor SD. A study of discomfort with electrical stimulation. Phys Ther. 1992;72(6):410-21; discussion on 21-4.

26. Selkowitz DM. Improvement in isometric strength of the quadriceps femoris muscle after training with electrical stimulation. Phys Ther. 1985;65(2):186-96. PMid:3871529.

27. Grimby G, Wigerstad-Lossing I. Comparison of highand low-frequency muscle stimulators. Arch Phys Med Rehabil. 1989;70(12):835-8. PMid:2818156.

28. Brasileiro JS, Castro CES, Parizotto NA, Sandoval MC. Comparative study between the capacity or the torque generation and the sensorial discomforts produced by two forms of neuromuscular electrical stimulation in healthy subjects. Rev Iberoam Fisioter Kinesiol. 2001;4:56-65.

29. Laufer Y, Ries JD, Leininger PM, Alon G. Quadriceps femoris muscle torques and fatigue generated by neuromuscular electrical stimulation with three different waveforms. Phys Ther. 2001;81(7):1307-16. PMid:11444994.

30. Lyons CL, Robb JB, Irrgang JJ, Fitzgerald GK. Differences in quadriceps femoris muscle torque when using a clinical 
electrical stimulator versus a portable electrical stimulator. Phys Ther. 2005;85(1):44-51. PMid:15623361.

31. Scott WB, Causey JB, Marshall TL. Comparison of maximum tolerated muscle torques produced by 2 pulse durations. Phys Ther. 2009;89(8):851-7. PMid:19541774. http://dx.doi.org/10.2522/ptj.20080151

32. Gorgey AS, Dudley GA. The role of pulse duration and stimulation duration in maximizing the normalized torque during neuromuscular electrical stimulation. J Orthop Sports Phys Ther. 2008;38(8):508-16. PMid:18678958 PMCid:PMC2554670.

33. Gregory CM, Dixon W, Bickel CS. Impact of varying pulse frequency and duration on muscle torque production and fatigue. Muscle Nerve. 2007;35(4):504-9. PMid:17230536. http://dx.doi.org/10.1002/mus.20710

34. Alon G, Smith GV. Tolerance and conditioning to neuromuscular electrical stimulation within and between sessions and gender. J Sports Sci Med. 2005;4:395-405.

35. Rooney JG, Currier DP, Nitz AJ. Effect of variation in the burst and carrier frequency modes of neuromuscular electrical stimulation on pain perception of healthy subjects. Phys Ther. 1992;72(11):800-6; discussion 7-9. PMid:1409877.

36. Avila MA, Brasileiro JS, Salvini TF. Electrical stimulation and isokinetic training: effects on strength and neuromuscular properties of healthy young adults. Rev Bras Fisioter. 2008;12(6):435-40. http://dx.doi. org/10.1590/S1413-35552008005000006

37. Faller L, Nogueira GN No, Button VLSN, Nohama P. Avaliação da fadiga muscular pela mecanomiografia durante a aplicação de um protocolo de EENM. Rev Bras Fisioter. 2009;13(5):422-9. http://dx.doi.org/10.1590/ S1413-35552009005000057

38. Kong PW, Van Haselen J. Revisiting the influence of hip and knee angles on quadriceps excitation measured by surface electromyography. ISMJ. 2010;11(2):313-23.
39. Portney LG, Watkins MP. Foundations of Clinical Research. 2nd ed. Upper Saddle River: Prentice Hall Health; 2000.

40. Cohen J. Statistical Power Analysis for the Behavioral Sciences. 2nd ed. Hillsdale: Earlbaum; 1988.

41. Li CL, Bak A. Excitability characteristics of the A- and C-fibers in a peripheral nerve. Exp Neurol. 1976;50(1):67-79. http://dx.doi.org/10.1016/0014-4886(76)90236-3

42. Howson DC. Peripheral neural excitability. Implications for transcutaneous electrical nerve stimulation. Phys Ther. 1978;58(12):1467-73. PMid:217029.

43. Alon G, Allin J, Inbar GF. Optimization of pulse charge and pulse duration during transcutaneous electrical nerve stimulation. Aust J Physiother. 1983;29:195-201.

44. Laufer Y, Elboim M. Effect of burst frequency and duration of kilohertz-frequency alternating currents and of low-frequency pulsed currents on strength of contraction, muscle fatigue, and perceived discomfort. Phys Ther. 2008;88(10):1167-76. PMid:18703676. http:// dx.doi.org/10.2522/ptj.20080001

45. Miller MG, Cheatham CC, Holcomb WR, Ganschow R, Michael TJ, Rubley MD. Subcutaneous tissue thickness alters the effect of NMES. J Sport Rehabil. 2008;17(1):6875. PMid: 18270388.

\section{Correspondence}

\section{Richard E. Liebano}

Universidade Cidade de São Paulo Programa de Pós-graduação em Fisioterapia Rua Cesário Galeno, 448/475, Tatuapé CEP 03071-000, São Paulo, SP, Brasil e-mail: liebano@gmail.com 